\title{
ANALISIS RISIKO PEMBANGUNAN UNDERPASS DEWA RUCI
}

I Gede Trisna Sura Nata ${ }^{1}$, I G. A. Adnyana Putera², Gd. Astawa Diputra ${ }^{2}$

\begin{abstract}
Abstrak:Pembangunan Underpass Dewa Ruci merupakan suatu usaha yang dilakukan pemerintah untuk meningkatkan aksesibilitas dalam mendukung pertumbuhan ekonomi serta meningkatkan kesejahteraan masyarakat. Kegiatan pembanguanUnderpass Dewa Ruci dapat memunculkan berbagai risiko, sehingga dilakukan penelitian untuk mengidentifikasi risiko, menilairisiko dengan analisis tingkat penerimaan risiko, mitigasi risiko dan kepemilikan risiko dominan.
\end{abstract}

Penelitian ini dilakukan dengan metode deskriptif kualitatif yaitu penelitian di lapangan dengan berpedoman pada kajian pustaka dan data penunjang. Pengumpulan data dilakukan dengan penyebaran kuesioner kepada responden menggunakan metode purposive sampling yaitu hanya memilih responden yang berkompeten dan berpengalaman(expert)mengenai kemungkinankemungkinan risiko yang terjadi pada saat pelaksanaan pembangunan Underpass Dewa Ruci.Penelitian dilakukandikawasan proyek pembangunan Underpass Dewa Ruci Jalan Baypass Ngurah Rai, Badung pada bulan Maret 2013 - Juni 2013.

Hasil penelitian menunjukkan adanya 99 risiko yang teridentifikasi dan terdapat 46 (46,46\%) risiko kategori dominan. Risiko dominan paling banyak ditemukan pada risiko proyek.Terdapat 105 tindakan mitigasi pada risiko dominan dengan 19 tindakan mitigasi pada risiko yang tidak dapat diterima.Kepemilikan risiko dominan paling banyak adalah pihak kontraktor yaitusebanyak 41 risiko (58,57\%) dengan tujuh risiko yang tidak dapat diterima. Risiko-risiko dominan tersebut misalnya terganggunya pelaksanaan konstruksi karena kepadatan lalu lintas tindakan mitigasinya adalah melakukan pengaturan lalu lintas bersama instansi terkait dan melakukan sebagian besar pekerjaan utama diluar jam sibuk lalu lintas sedangkan kepemilikan risikonya adalah pihak kontraktor.elevasi muka air tanah yang dangkal tindakan mitigasinya adalah menyiapkan sumur dewatering dan menyiapkan pompa serta mendahulukan mengerjakan saluran drainase sedangkan kepemilikan risikonya adalah kontraktor.

Kata kunci: identifikasi risiko, mitigasi risiko, risiko dominan, kepemilikan risiko, Underpass Dewa Ruci.

\section{RISK ANALYSIS TOWARD THE CONSTRUCTION OF DEWA RUCI UNDERPASS}

\begin{abstract}
The construction of Dewaruci Underpass was an attempt by the government to improve accessibility to support economic growth as well as to improve social welfare. The construction activities of Dewaruci Underpass can bring a wide range of risks, therefore it was conducted a research to identify the risks, assess the risks by analyzing the level of risk acceptance, risk mitigation and ownership of the dominant risk.

This research was conductedbyqualitativedescriptivemethod, namely the field research, based on theliterature reviewandsupporting data. Data was collected bydistributing questionnaires tothe respondentsusingpurposive sampling method, whichsimplyselectingrespondentswho were competentandexperienced(expert) about the possiblerisksthatoccurduring theexecution ofthe construction of Dewaruci Underpass. The study was conductedin the area ofdevelopment projects of Dewaruci Underpass, JalanNgurahRaiBypass, Badung from March 2013toJune 2013.

The results showedthat there were99risks identifiedand46(46.46\%) of dominantriskcategory. The dominantrisks were most prevalentinthe projectrisks. There were105measuresto mitigatetheriskdominantwith 19mitigationmeasuresatan unacceptablerisk. Mostdominantrisksweretherisks ofcontractorsof41(58.57\%) withsevenunacceptable risks.Thedominantrisksfor examples:disruption ofconstructiondue tothe density oftraffic, the mitigation measures were doingtraffic controlalong with the relevant agenciesandcarried out most ofthe majorworksoutsiderush hourtrafficandthe risk wasborne bythe contractor. Groundwater levelswereshallow, the mitigation measureswerepreparingdewateringwellsandthe pumpandput thework onthe drainagechannel, andthe risk wasborne bythe contractor.
\end{abstract}

Keywords: risk identification, riskmitigation, the dominantrisk, riskinsurer, Underpass of Dewaruci.

\footnotetext{
${ }^{1}$ Mahasiswa Program Studi Magister Teknik Sipil, Program Pascasarjana Universitas Udayana, Denpasar

${ }^{2}$ Staf Pengajar Program Magister Teknik Sipil, Program Pascasarjana, Universitas Udayana, Denpasar
} 


\section{PENDAHULUAN}

\section{Latar Belakang}

Pulau Bali merupakan salah satu daerah tujuan wisata nusantara maupun manca negara di Indonesia.Bagi masyarakat regional, Bali juga dijadikan tujuan mencari pekerjaan.Kondisi tersebut mengakibatkan pertambahan penduduk di Bali semakin hari semakin meningkat.Tercatat jumlah penduduk Bali pada tahun 2011 adalah 3.572.831 jiwa (Bali dalam Angka, 2012). Kepadatan penduduk terbanyak di Provinsi Bali terjadi di Kotamadya/ Kota Denpasar danKabupaten Badung.

Kota Denpasar menjadi pusat kegiatan masyarakat baik dalam pendidikan, politik dan ekonomi, sehingga Kota Denpasar menjadi tujuan bagi masyarakat untuk menempuh jenjang pendidikan dan mencari penghasilan.Sedangkan Kabupaten Badung merupakan salah satu tujuan utama pariwisata nasional dan internasional. Kondisi ini menyebabkan Kota Denpasar dan Kabupaten Badung mengalami masalah kepadatan penduduk yang berpengaruh terhadap banyaknya penambahan kendaraan bermotor untuk mempermudah proses mobilisasi seharihari sehingga hal tersebut menjadi faktor utama kemacetan.

Kemacetan yang terjadi juga dipengaruhi oleh faktor kurangnya jalur mobilisasi seperti keberadaan simpang tak sebidang, contohnya flyover (jalan layang) dan underpass (jalan bawah tanah).Salah satu, jalur mobilisasi yang sering mengalami kemacetan adalah Simpang Dewa Ruci terutama pada jam-jam sibuk (peak hour).

Simpang Dewa Ruci adalah salah satu simpang utama yang menghubungkan antara Denpasar, Kuta, Jimbaran dan Nusa Dua. Pada arus jam puncak terjadi kemacetan di Simpang Dewa Ruci yang makin lama semakin parah. Dalam rangka mengatasi kemacetan yang sering terjadi dan guna mendukung suksesnya pelaksanaan Event Internasional di Bali yaitu APEC 2013, Bali Summer Summit 2013 dan AFTA 2015, Kementerian Pekerjaan Umum Direktorat Jenderal Bina Marga, melalui Satuan Kerja Pelaksanaan Jalan Nasional Metropolitan Denpasar, melaksanakan pembangunan Underpass Simpang Dewa Ruci (Pejabat Pembuat Komitmen Simpang Dewa Ruci Satuan Kerja Pelaksanaan Jalan Nasional Metropolitan Denpasar, 2011).

Underpass Dewa Ruci merupakan Underpass pertama yang dibangun di Pulau Bali. Letak proyek pembangunan Underpass
Dewa Ruci yang strategis menarik perhatian berbagai kalangan baik sektor pariwisata, media cetak maupun elektronik dan masyarakat umum.Berbagai risiko dapat timbul pada setiap tahapan konstruksi terutama pada saat pelaksanaan dan operasional, sehingga dapat menjadi risiko bagi pihak owner, pelaksana dan masyarakat pengguna seperti pada beberapa penelitian yang telah dilakukan. Penelitian tersebut antara lain Analisis Risiko pada Proyek Pembangunan Sentral Parkir di Pasar Badung oleh Mahadipta (2010), Analisis Risiko pada Pembangunan Pusat Pemerintahan Kabupaten Badung (Sudiatmika, 2010), serta penelitian oleh Ratnaningsih dan Pangapuri (2014), tentang Analisis Risiko Manajemen Konstruksi Pembangunan Waduk Bajulmati BanyuwangiJawa Timur.

Pada tahap pelaksanaan pekerjaan Underpass Dewa Ruci, terdapat beberapa kendala antara lain sulitnya pengaturan lalu lintas pada saat pekerjaan proyek dan keterlambatan pihak kontraktor karena berbagai masalah di lapangan. Kendala tersebut harus dipertimbangkan untuk dapat meminimalkan timbulnya risiko dan ketidakpastian dalam pembangunan Underpass Dewa Ruci.

Berdasarkan latar belakang tersebut, maka dilakukan penelitian tentang analisis risiko pembangunan Underpass Dewa Ruci, karena Underpass Dewa Ruci merupakan sarana publik yang sangat vital. Diperlukan adanya manajemen risiko yaitu suatu pendekatan mengenai risiko atau ketidakpastian dengan melakukan identifikasi, analisis dan mitigasi untuk meminimalkan risiko yang akan terjadi.

\section{Rumusan Masalah}

1. Apakah risiko yang teridentifikasi pada tahap pelaksanaan pada proyek pembangunan Underpass Dewa Ruci?

2. Apakah risiko yang termasuk kategori dominan (major risk) pada proyek pembangunan Underpass Dewa Ruci?

3. Bagaimana cara mengelola atau melakukan mitigasi risiko yang ada untuk meminimalkan hal hal negatif yang mungkin terjadi?

4. Siapakah yang bertanggung jawab terhadap risiko yang terjadi (ownership of risk)? 


\section{Tujuan Penelitian}

1. Mengidentifikasi risiko pada tahap pelaksanaan pada proyek pembangunan Underpass Dewa Ruci.

2. Mengetahui risiko yang termasuk kategori dominan (major risk) pada proyek pembangunan Underpass Dewa Ruci.

3. Melakukan pengelolaan atau mitigasi risiko yang ada untuk meminimalkan hal hal negatif yang mungkin terjadi.

4. Mengetahui penanggung jawab risiko yang terjadi (ownership of risk).

\section{Manfaat Penelitian}

Hasil dari penelitian ini akan memberikan informasi mengenai risiko yang teridentifikasi pada tahap pelaksanaan, mengetahui risiko dominan, pengelolaan atau mitigasi risiko untuk meminimalkan hal negatif yang mungkin terjadi, serta mengetahui penanggung jawab risiko yang terjadi pada proyek pembangunan Underpass Dewa Ruci.

\section{METODE PENELITIAN}

\section{Rancangan Penelitian}

Rancangan Penelitian ini secara umum dilakukan dengan metode deskriptif kualitatif.Metode yang digunakan berupa penelitian di lapangan, berpedoman kepada kajian pustaka dan data-data penunjang yang ada.Hasil dan pembahasan masalah diperoleh dengan metode wawancara dan survey untuk memperoleh data berupa opini dari responden serta pihak-pihak yang berkompeten dan berpengalaman(expert)mengenai

kemungkinan-kemungkinan risiko yang terjadi.

\section{Lokasi dan Waktu Penelitian}

Lokasi penelitian ini difokuskan pada Kawasan Proyek pembangunan Underpasss Dewa Ruci di Jalan Baypass Ngurah Rai, Badung. Waktu penelitian ini adalah bulan Maret 2013- Juni 2013

\section{Jenis dan Sumber Data}

Metode pengambilan sampel melalui penyebaran kuesioner pada penelitian ini menggunakan purposive sampling yaitu dengan memilih responden hanya pihak-pihak yang berkompeten dan berpengalaman(expert)mengenai

kemungkinan-kemungkinan risiko yang terjadi pada saat pelaksaan pembangunan Underpass Dewa Ruci (Sugiyono, 2008).
Pada penelitian ini diperlukan data yang jenis dan sumbernya diklasifikasikan menjadi data primer (pemberian kuesioner yang dipandu dalam pengisiannya kepada pihakpihak yang berkompeten dan berpengalaman) dan data sekunder.

\section{Instrumen Penelitian}

Pengumpulan data primer dilakukan dengan wawancara dansurvey menggunakan kuesioner sebagai instrumen penelitian.

\section{Teknik Pengumpulan Data}

Teknik pengumpulan data dilakukan sebagai berikut:

1. Identifikasi Risiko

Identifikasi risiko yang terjadi dalam pembangunan Underpass Dewa Ruci didapat dengan merujuk pada penelitian sejenis sebelumnya, wawancara dengan pihak yang berkompeten memberikan masukan terhadap risiko-risiko yang terjadi dalam pembangunan Underpass Dewa Ruci, melakukan pengamatan langsung di lapangan dan brainstorming sehingga dapat dibentuk menjadi sebuah kuesioner.

2. Pembuatan Kuesioner

Pada penelitian ini digunakan bentuk kuesioner dengan pertanyaan semi tertutup yaitu pertanyaan yang sebagian telah disediakan pilihan jawabannya namun pada bagian lain juga meminta jawaban yang berasal dari responden,sehinggamemungkinkan untuk menambah risiko yang belum teridentifikasi.

3. Survey Pendahuluan

Dilakukan survey pendahuluan berupa penyebaran kuisioner kepada 10 orang responden untuk diuji validitas dan reliabilitas instrument penelitian.

4. Penentuan Responden

Pihak yang dijadikan responden adalah pihak yang terlibat dalam proyek sebanyak 30 orang (Tabel 1).

5. Pengumpulan Data Primer

Data primer dalam penelitian ini diperoleh dari hasil responden mengenaiidentifikasi risiko terhadap kemungkinan(likelihood) dan konsekuensi (consequences) yang terjadi pada pembangunan underpass Dewa Ruci. Penilaian terhadap kemungkinan terjadinya hal-hal yang menimbulkan kerugian dapat didefinisikan dalam Tabel 2dan pengukuran besarnya pengaruh variabel risiko terhadap kegiatan pembangunan Underpass Dewa Ruci, 
menggunakan skala seperti pada Tabel 3 (Godfrey, 1996).

6. Pengumpulan Data Sekunder
Data sekunder diperoleh dari literatur seperti jurnal (e-journal), paper, gambar DED,RAB, RKS, kontrak kerja dan penelitian-penelitian sebelumnya.

Tabel1.Responden dalam Penelitian

\begin{tabular}{|c|c|c|c|}
\hline No. & LEMBAGA & Responden & $\begin{array}{l}\text { Jumlah } \\
\text { (orang) }\end{array}$ \\
\hline \multirow[t]{4}{*}{1.} & \multirow{4}{*}{$\begin{array}{l}\text { Balai Pelaksanaan Jalan Nasional } \\
\text { VIII }\end{array}$} & Kepala Balai & 1 \\
\hline & & Kepala Seksi Perencanaan & 1 \\
\hline & & Kepala Seksi Pelaksanaan & 1 \\
\hline & & Kepala Seksi PSP3 & 1 \\
\hline \multirow[t]{3}{*}{2.} & \multirow{3}{*}{$\begin{array}{l}\text { Satuan Kerja Perencanaan dan } \\
\text { Pengawasan Provinsi Bali }\end{array}$} & Kepala Satuan Kerja & 1 \\
\hline & & $\begin{array}{l}\text { Pejabat Pembuat Komitmen Metropolitan } \\
\text { Denpasar }\end{array}$ & 1 \\
\hline & & Asisten Perencanaan & 1 \\
\hline \multirow[t]{5}{*}{3.} & \multirow{5}{*}{$\begin{array}{l}\text { Satuan Kerja Pelaksanaan Jalan } \\
\text { Nasional Metropolitan Denpasar }\end{array}$} & Kepala Satuan Kerja & 1 \\
\hline & & Asisten Pelaksanaan & 1 \\
\hline & & $\begin{array}{l}\text { Pejabat Pembuat Komitmen Simpang Dewa } \\
\text { Ruci }\end{array}$ & 1 \\
\hline & & Kepala Pengawas Lapangan & 1 \\
\hline & & Pengawas Lapangan & 2 \\
\hline \multirow[t]{2}{*}{4.} & Konsultan & Team Leader & 1 \\
\hline & $\begin{array}{l}\text { Pembangunan Underpass Dewa } \\
\text { Ruci }\end{array}$ & Highway Engineer & 1 \\
\hline \multirow[t]{5}{*}{5.} & Konsultan & Pengawas Arsitek & 1 \\
\hline & Pembangunan Underpass Dewa & Pengawas Mecanikal & 1 \\
\hline & Ruci & Site Engineer & 1 \\
\hline & & Quantity Engineer & 1 \\
\hline & & Geothecnic Engineer & 1 \\
\hline \multirow[t]{7}{*}{6.} & Kontraktor Pelaksana & Project Manager & 1 \\
\hline & & Deputi Project Manager & 1 \\
\hline & & Project Engeneering Manager & 1 \\
\hline & & Project Production Manager Infrastruktur & 1 \\
\hline & & Project Production Manager Underpass & 1 \\
\hline & & Cost Control & 1 \\
\hline & & Quality Control & 1 \\
\hline \multirow[t]{2}{*}{7.} & \multicolumn{2}{|c|}{ Tim Ahli Jalan dan Jembatan Kementerian Pekerjaan Umum } & 3 \\
\hline & & Jumlah & 30 \\
\hline
\end{tabular}




\section{Analisis Data}

\section{Analisis Relabilitas dan Validitas}

Adapun pengujian validitas dan reliabilitas dapat dijelaskan sebagai berikut:

1. Pengujian Validitas Instrumen

Pendapat dari para ahli (judgement experts) dapat digunakan sebagai pengujian validitas kontruksi.Dalam menguji validitas alat ukur, terlebih dahuludicarihargakorelasiantarabagianbagiandari alat ukur secara keseluruhan dengan cara mengkorelasikan setiap butir alat ukur dengan score total yang merupakan jumlah score tiap butir dengan rumus Pearson Product Moment(Arikunto, 1997).

\section{Rumus Pearson Product Moment.}

$r_{x y}=\frac{n \sum X Y-\left(\sum X\right)\left(\sum Y\right)}{\sqrt{\left\{n \sum X^{2}-\left(\sum X\right)^{2}\right\}\left\{n \sum Y^{2}-\left(\sum Y\right)^{2}\right\}}}$

\section{Keterangan:}

$r_{\mathbf{x y}}=$ Koefisien Korelasi Product Moment

$\mathrm{n}=$ Jumlah sampel responden

$X=$ Score item instrumen

$Y=$ Score total tiap rsponden

2. Pengujian Reliabilitas Modus Jawaban Responden

Metode pengujian reliabilitas instrumen dilakukan dengan mengunakan cara metode belah dua (Split Half Method) yang dianalisis dengan rumus Spearman Brown(Riduwan, 2008).

$$
\begin{gathered}
\text { Rumus Spearman Brown } \\
r 11=\frac{2 . r b}{1+r b}
\end{gathered}
$$

\section{Keterangan:}

r11= Koefisien reliabilitas internal seluruh item $\mathrm{rb}=$ Koefisien Product Moment antara belahan

Tabel 2.Tingkat dan Skala Frekuensi (Likehood)

\begin{tabular}{lcc}
\hline \multicolumn{1}{c}{ TINGKAT } & PELUANG & SKALA \\
FREKUENSI & & 5 \\
\hline Sangat sering & $\mathrm{X} \geq 80 \%$ & 4 \\
Sering & $60 \% \leq \mathrm{X}<80 \%$ & 3 \\
Kadang- & $40 \% \leq \mathrm{X}<60 \%$ & 3 \\
kadang & & 2 \\
Jarang & $20 \% \leq \mathrm{X}<40 \%$ & 1 \\
Sangat jarang & $\mathrm{X}<20 \%$ & 1 \\
\hline
\end{tabular}

Tabel 3.Tingkat dan Skala Konsekuensi (Consequences)

\begin{tabular}{lcc}
\hline \multicolumn{1}{c}{ TINGKAT } & PELUANG & SKALA \\
KONSEKUENSI & & 5 \\
\hline Sangat besar & $\mathrm{X} \geq 80 \%$ & 4 \\
Besar & $45 \% \leq \mathrm{X}<80 \%$ & 3 \\
Sedang & $15 \% \leq \mathrm{X}<45 \%$ & 2 \\
Kecil & $5 \% \leq \mathrm{X}<15 \%$ & 1 \\
Sangat kecil & $\mathrm{X}<5 \%$ & \\
\hline
\end{tabular}

\section{Penerimaan Risiko (Risk Acceptability)}

Analisis tingkat penerimaan risiko tergantung dari nilai yang diperoleh dari skala kemungkinan (likelihood) dengan konsekuensi (consequensces) (Godfrey, 1996; Suputra, 2005; Ratnaningsih dan Pangapuri, 2014). Penilaian Tingkat Penerimaan Risiko (Assesment of Risk Acceptability) dapat dilihat pada Tabel 4 dan skala penerimaan risiko pada Tabel 5 (Godfrey, 1996)..

Tabel 4. Penilaian Tingkat Penerimaan Risiko (Assesment of Risk Acceptability)

\begin{tabular}{cccccc}
\hline $\begin{array}{c}\text { Consequence/ Catastropic5 } \\
\text { Likehood }\end{array}$ & Critical4 & Serious3 & Marginal2 & Negligible1 \\
\hline & Unaceptable & Unaceptable & Unaceptable & Undesirable Undesirable \\
Frequent5 & $(25)$ & $(20)$ & $(15)$ & $(10)$ & $(5)$ \\
& Unaceptable & Unaceptable & Undesirable & Undesirable & Aceptable \\
Probable4 4 & $(20)$ & $(16)$ & $(12)$ & $(8)$ & $(4)$ \\
& Unaceptable & Undesirable & Undesirable & Undesirable & Aceptable \\
Occasional3 3 & $(15)$ & $(12)$ & $(9)$ & $(6)$ & $(3)$ \\
& Undesirable & Undesirable & Undesirable & Aceptable & Negligible \\
Remote2 & $(10)$ & $(8)$ & $(6)$ & $(4)$ & $(2)$ \\
& Undesirable & Aceptable & Aceptable & Negligible & Negligible \\
Imporable 1 & $(5)$ & $(4)$ & $(3)$ & $(2)$ & $(1)$ \\
\hline
\end{tabular}

Dari Tabel 4 dapat diuraikan tingkat penerimaan risiko sebagai berikut:

1. Unaceptable adalah risiko yang tidak dapat diterima dan harus dihilangkan.

2. Undesirable adalah risiko yang tidak diharapkan dan harus dihindari.

3. Aceptable adalah risiko yang dapat diterima.

4. Negligible adalah risiko yang sepenuhnya dapat diterima.

Tabel 5.Skala Penerimaan Risiko

\begin{tabular}{cc}
\hline Indikator & SkalaPenerimaan Risiko \\
Penerimaan Risiko & \\
\hline Unaceptable & $\mathrm{X} \geq 15$ \\
Undesirable & $5 \leq \mathrm{X}<15$ \\
Aceptable & $3 \leq \mathrm{X}<5$ \\
Negligible & $\mathrm{X}<3$ \\
\hline
\end{tabular}

Dari hasil skala penerimaan risiko ini dilakukan suatu evaluasi terhadap risiko yang 
telah diidentifikasi berdasarkan kuisioner, sehingga

unaceptabledanundesirablememerlukan

tindakan mitigasi.

\section{Penilaian Kepemilikan Risiko}

Kepemilikan tanggung jawab risikoberdasarkan prinsip yang dikembangkan oleh Flanagan and Norman (1993),yaitu:

1. Pihak-pihak yang mempunyai kontrol terbaik terhadap suatu kejadian yang menimbulkan risiko.

2. Pihak yang menangani ketika risiko tersebut muncul.

3. Pihak yang bertanggung jawab jika risiko tidak terkontrol.

4. Jika risiko di luar kontrol semua pihak, maka diasumsikan sebagai risiko bersama.

\section{HASIL DAN PEMBAHASAN}

\section{Identifikasi Risiko PembangunanUnderpass Dewa Ruci}

Terdapat 99 risiko yang teridentifikasi dalam pembangunan Underpass Dewa Ruci.Sebanyak 44 risiko didapatkan dengan merujuk pada penelitian sejenis (Mahadipta, 2014) dan 55 risiko dengan melakukan pengamanatan langsung (brainstorming).Risiko yang teridentifikasi dikelompokkan menjadi 11 kategori berdasarkan sumber risiko.Dari seluruh risiko yang teridentifikasi, maka persentase jumlah risiko berdasarkan sumber risiko dapat dilihat pada Tabel 6.

Menurut Godfrey (1996),identifikasi risiko bersumber dari aktifitas yang dapat dikategorikan menjadi risiko politis, lingkungan, pemasaran, ekonomi, keuangan, alami, teknis, proyek, manusia, kriminal dan keselamatan. Pada hasil identifikasi, risiko yang paling banyak terjadi adalah risiko proyek yaitu 31 risiko (31,31\%). Jumlah risiko terbesar yang bersumber dari aktifitas proyek menunjukkan bahwa risiko-risiko khususnya pada tahap pelaksanaan lebih banyak muncul karena berkaitan langsung dengan teknis pekerjaan di lapangan dan berhubungan dengan lingkungan sekitar proyek dengan segala aktifitas dan kendalanya.

Tabel 6. Persentase Jumlah Risiko Berdasarkan Sumber Risiko

\begin{tabular}{llcc}
\hline No. & Sumber Risiko & $\begin{array}{c}\text { Jumlah } \\
\text { Risiko }\end{array}$ & $\begin{array}{c}\text { Persentase } \\
\mathbf{( \% )}\end{array}$ \\
\hline 1 & Politis & 8 & 8,08 \\
2 & Lingkungan & 9 & 9,09 \\
3 & Pemasaran & 3 & 3,03 \\
4 & Ekonomi & 3 & 3,03 \\
5 & Keuangan & 6 & 6,06 \\
6 & Alami & 3 & 3,03 \\
7 & Teknis & 5 & 5,05 \\
8 & Proyek & 31 & 31,31 \\
9 & Manusia & 14 & 14,14 \\
10 & Kriminal & 10 & 10,10 \\
11 & Keselamatan & 7 & 7,07 \\
& Jumlah Total & $\mathbf{9 9}$ & $\mathbf{1 0 0}$ \\
\hline
\end{tabular}

\section{Risiko-risiko Dominan (Major Risk)}

Penilaian risiko didapatkan dengan mengalikan nilai kemungkinandan konsekuensi.Berdasarkan hasil perkalian tersebut dan analisis modus penilaian responden terhadap risiko berdasarkan sumber risiko dapat dijabarkan distribusi peneriman risiko pada Tabel 7. Berdasarkan Tabel 7 diperoleh nilai risiko untuk menentukan tingkat penerimaan risiko sebagai berikut: unacceptable sebanyak tujuh risiko, undesirable 39 risiko, acceptable 33 risiko dan negligible 20 risiko. Risiko-risiko yang bersifat dominan adalah risiko-risiko yang termasuk kategori unacceptable dan undesirable. Didapatkan jumlah risiko dominan sebanyak 46 (46,46\%).

Keberadaan risiko-risiko dominan akan berpengaruh besar terhadap pembangunan Underpass Dewa Ruci. Persentase risiko-risiko dominan (46,46\%) menunjukkan bahwa banyak risiko yang tidak dapat diterima dan tidak diharapkan.

Tabel 7. Distribusi Penerimaan Risiko untuk Setiap Sumber Risiko

\begin{tabular}{|c|c|c|c|c|c|c|c|c|c|c|c|}
\hline \multirow{3}{*}{ No } & \multirow{3}{*}{ Sumber Risiko } & \multirow{2}{*}{\multicolumn{2}{|c|}{ Identifikasi Risiko }} & \multicolumn{8}{|c|}{ Tingkat Penerimaan Risiko (Risk Acceptability) } \\
\hline & & & & \multicolumn{2}{|c|}{ Unacceptable } & \multicolumn{2}{|c|}{ Undesirable } & \multicolumn{2}{|c|}{ Acceptable } & \multicolumn{2}{|c|}{ Negligible } \\
\hline & & Jml & $\%$ & Jml & $\%$ & Jml & $\%$ & Jml & $\%$ & Jml & $\%$ \\
\hline 1. & Politis & 8 & $8.08 \%$ & 2 & $2.02 \%$ & 2 & $2.02 \%$ & 1 & $1.01 \%$ & 3 & $3.03 \%$ \\
\hline 2. & Lingkungan & 9 & $9.09 \%$ & 1 & $1.01 \%$ & 6 & $6.06 \%$ & 2 & $2.02 \%$ & 0 & $0.00 \%$ \\
\hline 3. & Pemasaran & 3 & $3.03 \%$ & 0 & $0.00 \%$ & 1 & $1.01 \%$ & 1 & $1.01 \%$ & 1 & $1.01 \%$ \\
\hline 4. & Ekonomi & 3 & $3.03 \%$ & 0 & $0.00 \%$ & 0 & $0.00 \%$ & 2 & $2.02 \%$ & 1 & $1.01 \%$ \\
\hline 5. & Keuangan & 6 & $6.06 \%$ & 0 & $0.00 \%$ & 1 & $1.01 \%$ & 5 & $5.05 \%$ & 0 & $0.00 \%$ \\
\hline 6. & Alami & 3 & $3.03 \%$ & 1 & $1.01 \%$ & 1 & $1.01 \%$ & 0 & $0.00 \%$ & 1 & $1.01 \%$ \\
\hline 7. & Teknis & 5 & $5.05 \%$ & 2 & $2.02 \%$ & 3 & $3.03 \%$ & 0 & $0.00 \%$ & 0 & $0.00 \%$ \\
\hline 8. & Proyek & 31 & $31.31 \%$ & 1 & $1.01 \%$ & 14 & $14.14 \%$ & 15 & $15.15 \%$ & 1 & $1.01 \%$ \\
\hline 9. & Manusia & 14 & $14.14 \%$ & 0 & $0.00 \%$ & 8 & $8.08 \%$ & 4 & $4.04 \%$ & 2 & $2.02 \%$ \\
\hline 10. & Kriminal & 10 & $10.10 \%$ & 0 & $0.00 \%$ & 1 & $1.01 \%$ & 2 & $2.02 \%$ & 7 & $7.07 \%$ \\
\hline 11. & Keselamatan & 7 & $7.07 \%$ & 0 & $0.00 \%$ & 2 & $2.02 \%$ & 3 & $3.03 \%$ & 2 & $2.02 \%$ \\
\hline & Jumlah & 99 & $100 \%$ & 7 & $7.07 \%$ & 39 & $39.39 \%$ & 35 & $35.35 \%$ & 18 & $18.18 \%$ \\
\hline
\end{tabular}




\section{Mitigasi Risiko (Risk Mitigation)}

Mitigasi risiko dapat dilakukan dengan menahan risiko (risk retention),mengalihkan risiko (risik transfer), mengurangi risiko (risk reduction),dan menghindari risiko (risk avoidance).Tidakan mitigasi dilakukan pada risiko yang termasuk kategori risiko dominan, Tindakan-tindakan mitigasi yang dilakukan didapat dari hasil analisis dan wawancara dari pihak berkompeten.Pada risiko unacceptabledilakukan 19 tindakan mitigasi dan 86 tindakan mitigasi terhadap risiko undesirable.

\section{Kepemilikan Risiko (Ownership of Risk)}

Berdasarkan risiko-risiko yang teridentifikasi dan telah dilakukan mitigasi, maka dapat diketahui pihak-pihak yang terlibat di dalam proses pelaksanaan pembangunan Underpass Dewa Ruci. Pihak-pihak yang terlibat dalam pembangunan Underpass Dewa Ruci adalah Kementerian Pekerjaan Umum Direktorat Jenderal Bina Marga sebagai owner, Konsultan Perencana, Konsultan Pengawas dan Kontraktor.Hasil kepemilikan risiko untuk risiko dominan pada pembangunan Underpass Dewa Ruci dapat dilihat dalam Tabel 8.

Kepemilikan risiko terbesar untuk risiko-risiko dominan pada pembangunan Underpass Dewa Ruci adalah kontraktor dengan jumlah tujuh risiko unacceptable dan 34 risiko yang undersirable.Kepemilikan risiko terbesar menjadi tanggung jawab dari pihak kontraktor karena sebagian besar identifikasi risiko terjadi pada tahap pelaksanaan pekerjaan khususnya risiko yang bersumber dari risiko proyek.Selain itu terdapat risiko yang juga menjadi tanggung jawab bersama antara owner, konsultan perencana, konsultan pengawas dan kontraktor.

Tabel 8. Kepemilikan Risiko untuk Risiko Dominan Pada Pembangunan UnderpassDewa

\begin{tabular}{clcc} 
Ruci & & & \\
\hline No. & $\begin{array}{c}\text { Kepemilikan } \\
\text { Risiko }\end{array}$ & Unaceptable & Undesirable \\
\hline 1. & Owner & 5 & 10 \\
2. & $\begin{array}{l}\text { Konsultan } \\
\text { Perencana }\end{array}$ & 1 & 1 \\
3. & $\begin{array}{l}\text { Konsultan } \\
\text { Pengawas }\end{array}$ & 2 & 10 \\
4. & Kontraktor & 7 & 34 \\
\hline
\end{tabular}

\section{SIMPULAN DAN SARAN \\ Simpulan}

Berdasarkan hasil dan pembahasan, ditarik kesimpulan:

1. Pada pelaksanaan pembangunan Underpass Dewa Ruci teridentifikasi sebanyak 99 risiko. Risiko yang teridentifikasi yaitu delapan risiko politis, sembilan risiko lingkungan, tiga risiko pemasaran, tiga risiko ekonomi, enam risiko keuangan, tiga risiko alami, lima risiko teknis, 31 risiko proyek, 14 risiko manusia, 10 risiko kriminal dan tujuh risiko keselamatan. Dari analisis risiko yang teridentifikasi terdapat tujuh risiko yang termasuk kategori unacceptable, 39 undesirable, 33 acceptable dan 20 risiko negligible.

2. Risiko dominan yang didapat sebanyak 46 $(46,46 \%)$, terdiri dari tujuh risiko unacceptable dan 39 risiko undesirable. Risiko unacceptable yaitu berita media cetak maupun elektronik yang bersifat kontra produktif terhadap pelaksanaan pembangunan Underpass Dewa Ruci, adanya masukan-masukan dari instansi lain yang berakibat adanya perubahan desain dan teknis pengerjaan, terganggunya kelancaran pekerjaan akibat tingginya tingkat kepadatan lalu lintas di sekitar lokasi pembangunan, elevasi muka air tanah yang sangat dangkal sehingga menyulitkan dalam pengerjaan proyek, arus lalu lintas yang padat sehingga pengalihan arus menimbulkan kemacetan, sulitnya berkoordinasi dengan pemilik utilitas terkait relokasi utilitas, dan adanya hambatan utilitas yang belum bisa direlokasi. Risiko undesirable paling banyak ditemukan pada kategori risiko proyek sebanyak 14 risiko yaitu ketidaksesuaian antara volume pekerjaan di dalam BQ dan kondisi di lapangan, adanya perubahan desain akibat penyesuaian dengan kondisi lapangan, produktivitas tenaga kerja yang minimal sehingga mempengaruhi progress work, keterlambatan mobilisasi peralatan, kontraktor mengabaikan instruksi pengawas pekerjaan teknik (owner dan konsultan), instruksi pengawas teknik tidak diikuti dengan perincian tertulis, tenaga kerja yang diperlukan kurang mencukupi, terjadinya keterlambatan target rencana 
penyelesaian pekerjaan, kurangnya pasokan daya listrik di lapangan, kapasitas pompa air yang kurang memadai sehingga menyulitkan pekerjaan, adanya bahaya longsoran pada saat pelaksanaan proyek, adanya ketidak tepatan pemasangan bored pile, kurangnnya pagar pengaman proyek yang dapat mengakibatkan kecelakaan terutama bahaya terjatuhnya kendaraan yang melintas pada saat penggalian underpass, dan pekerjaan tambah yang lebih besar dari 10 persen.

3. Tindakan mitigasi yang dilakukan untuk risiko-risiko yang termasuk dalam risiko dominan pada pembangunan Underpass Dewa Ruci dilakukan dengan tindakan mengurangi risiko (risk reduction) tanpa meninjau adanya risiko sisa (residual risk). Dilakukan 19 tindakan mitigasi untuk risiko unacceptabledan 86 untuk risiko undesirable. Salah satu tindakan mitigasi yang dilakukan pada risiko dominan adanya masukan-masukan dari instansi lain yang berakibat adanya perubahan desain dan teknis pengerjaan yaitu dengan melakukan kajian teknis bersama Kasatker Perencanaan dan Pengawasan Jalan Nasional (P2JN) Provinsi Bali untuk mengkaji masukan tersebut apakah sesuai dengan Tugas Pokok dan Fungsi (TUPOKSI) Kementerian Pekerjaan Umum Direktorat Jenderal Bina Marga, serta menunjang fungsi underpass dan apakah dapat diakomodir terhadap desain, waktu dan dana yang tersedia.

4. Tanggung jawab dan kepemilikan risiko dalam pembangunan Underpass Dewa Ruci yaitu owner (Kementerian Pekerjaan Umum Direktorat Jenderal Bina Marga) seperti kurangnya koordinasi antara instansi terkait dalam pengambilan keputusan yang dapat mempengaruhi pengerjaan proyek, konsultan perencana pada risiko ketidaksesuaian antara volume pekerjaan di dalam BQ dan kondisi di lapangan, konsultan pengawas pada risiko instruksi pengawas teknik tidak diikuti dengan perincian tertulis dan kontraktor pada risiko adanya kerusakan bangunan di sekitar proyek akibat proses kontruksi. Pada risiko unacceptable terdapat lima risiko tanggung jawab owner, satu konsultan perencana, dua konsultan pengawas dan tujuh kontraktor. Sedangkan pada risiko undesirable terdapat 10 risiko tanggung jawab owner, satu konsultan perencana, 10 konsultan pengawas dan 34 kontraktor. Tanggung jawab dan kepemilikan risiko terbesar dalam pembangunan Underpass Dewa ruci adalah Kontraktor sebanyak 41 risiko (58,57\%) dengan tujuh risiko unacceptable dan 34 risiko undesirable, sedangkan pemilik risiko terkecil adalah konsultan perencana yaitu dua risiko (2,86\%) masing-masing satu pada risiko unacceptable dan undesirable. Terdapat satu risiko yang menjadi tanggung jawab bersama antara owner, konsultan perencana, konsultan pengawas dan kontraktor yaitu adanya masukan-masukan dari instansi lain yang berakibat adanya perubahan desain dan teknis pengerjaan.

\section{Saran}

Saran-saran yang dapat disampaikan sebagai berikut:

1. Untuk menghindari atau memperkecil risiko yang terjadi pada proyek pembangunan Underpass Dewa Ruci kontraktor harus mempelajari lokasi proyek, karakteristik proyek, lingkup pekerjaan serta mengenali kemampuan diri dalam menyelesaikan pekerjaan tersebut.

2. Koordinasi antara pihak pihak yang terkait hendaknya dilaksanakan mulai dari tahap Perencanaan misalnya mengundang seluruh pihak atau instansi pemilik utilitas agar nantinya para pemilik utilitas dapat mempersiapkan diri dan mengalokasikan dana untuk relokasi. kemudian dalam tahap pelaksanaan misalnya selalu melakukan koordinasi pada setiap tahapan pelaksanaan pekerjaan seperti koordinasi dengan pihak kepolisian dan perhubungan terkait dengan lalu lintas dan koordinasi dengan Perusahaan Daerah Air Minum dan Perusahaan Listrik Negara (PLN) untuk pemindaan utilitas.

3. Hasil penelitian ini diharapkan dapat menjadi pedoman untuk penelitianpenelitian selanjutnya dalam mengidentifikasi risiko dan melakukan tindakan-tindakan mitigasi suatu pembangunan untuk mengurangi dampak negatif yang ditimbulkan, serta sebagai masukan ataupun bahan pertimbangan bagi pihak-pihak yang terkait dalam pembangunan Underpass Dewa Ruci maupun kegiatan pembangunan sejenis. 


\section{DAFTAR PUSTAKA}

Arikunto, 1997.Prosedur Penelitian.Jakarta : Rineka Cipta

Bali dalam Angka.2012.Luas Wilayah, Jumlah Rumahtangga, dan Jumlah Penduduk Hasil Registrasi Penduduk Menurut Kabupaten/ Kota di Bali Tahun 2011. Badan Pusat Statistik Provinsi Bali: Bali.

Flanagan, R., G. Norman. 1993. Risk Management and Construction. Cambridge University Press: Cambridge.

Godfrey, P.S. 1996. Control of Risk: A Guide to The Systematic Management of Risk from Construction. Construction Industry Research and Information Association (CIRIA): Westminster London.

Mahadipta, N. G. D. 2010. Analisis Risiko pada Proyek Pembangunan Sentral Parkir di Pasar Badung (tesis). Universitas Udayana: Denpasar.

Pejabat Pembuat Komitmen Simpang Dewa Ruci Satuan Kerja Pelaksanaan Jalan Nasional Metropolitan Denpasar.2011.Kontrak Paket Pembangunan Simpang Dewa Ruci (Multi Years Contract) KU.08.08/390/SPJNMD.SD/XI/2011.Denpasar.

Ratnaningsih, A., D.G.A. Pangapuri. 2014. Analisis Risiko Manajemen Konstruksi Pembangunan Waduk Bajulmati Banyuwangi-Jawa Timur. Seminar Nasional X Teknik Sipil ITS Surabaya "Inovasi Struktur dalam Menunjang Konektivitas Pulau di Indonesia”.ISBN 978-979-99327-9-2.

Riduwan. 2008. Metode dan Teknik Menyusun Tesis. CV. Alfabeta: Bandung.

Sudiatmika, I.W.A. 2010.Analisis Risiko pada Pembangunan Pusat Pemerintahan Kabupaten Badung (tesis). Universitas Udayana: Denpasar.

Sugiyono. 2008. Metode Penelitian Kuantitatif, Kualitatif dan $R \quad \& \quad D$. Bandung: Alfabeta.

Suputra, I.G.N.O. 2005.Manajemen Risiko pada Pelaksanaan Pembangunan Denpasar Sewerage Development Project (DSDP) di Denpasar (tesis). Universitas Udayana: Denpasar. 